\title{
Developing a Power Efficient Private Cloud Ready Infrastructure for Small-Medium Sized Enterprises
}

\author{
Emmanuel Kayode Akinshola Ogunshile \\ Department of Computer Science, University of the West of England, Bristol, U.K. \\ Emmanuel.Ogunshile@uwe.ac.uk
}

Keywords: Cloud Services, Solar energy, Energy storage, Digital systems.

\begin{abstract}
Digital technology is advancing and the means of powering it so. For small-medium enterprise (SME) to remain competitive in today's economic climate it is paramount they can respond to business challenges with agility and efficiency. Despite knowing this, many of today's SMEs retain legacy hardware and siloed infrastructures that are both expensive to maintain and incapable of being agile. These heterogeneous infrastructures offer no elasticity for its consumers and act as a barrier to its own innovation. Acquiring requisite budget to transform such digital infrastructure with high operational energy costs has proven an uphill struggle as there is a distinct lack of perceived benefits from undergoing such transformation program. However, amidst the various comparable options, claims, and features from different technology vendors available in the market there are true benefits applicable to all SMEs. To demonstrate how a solution such as moving to the cloud and or adopting solar power could benefit a SME's infrastructure, and operational costs, the requirements of a fictitious Marketing Agency have been analysed by a company specialised in cloud, virtualisation and solar power to introduce a framework suitable for any SME curious of the benefits presented by basic cloud principles, virtualised resources and renewable energy.
\end{abstract}

\section{INTRODUCTION}

Cloud computing is a field of study hindered by misunderstanding and confusion. This is due to the term Cloud being used to describe many services that aren't clouds. Cloud computing is more than server virtualization and, is best described by NIST in the following quote, "Cloud computing is a model for enabling ubiquitous, convenient, on-demand network access to a shared pool of configurable computing resources (e.g., networks, servers, storage, applications and services) that can be rapidly provisioned and released with minimal management effort or service provider interaction." (Brown, 2016)

To develop an understanding of cloud and its potential benefits to a SME the Cloud Company, "Infrastructure Revolutions Ltd", will be analysing the business challenges and requirements of a fictitious SME with the view to combat and or address these challenges using implementable Cloud solutions and solar technology. Though this paper pays homage to the fundamental benefits of moving to the cloud such as "simplified management lifecycles", the main area of focus for this paper will be on the everlasting benefits to an infrastructure's Power Consumption.

The example SME featured in this paper is a Marketing Agency with expendable income that has been allocated for internal growth. Its commonplace for SMEs to invest in internal growth so deciding how this income will be invested should outline a repeatable framework for businesses of a similar standing. Infrastructure Revolutions Ltd performing the IT overhaul are experts in the virtualization, cloud and solar market, meaning focus will go beyond converging the SME's Infrastructure.

To address the identified challenges and requirements of the fictitious SME, the paper has been organized as follows: Section one introduces the paper, Section two researches and analyses the SME, section three the fundamentals of cloud computing 
deployments, section four the cost analysis of implementing a private cloud solution, section five a cost benefit analysis of supporting an IT infrastructure via Solar power, section six the paper's proposed solution and section seven the conclusion.

\section{BUSINESS CASE}

Throughout this paper, the research will relate back to the fictitious business case outlined in this section. This is done to both provide direction for the research and to enhance the understanding of the implications of implementing cloud computing from a siloed infrastructure.

\subsection{Business Background}

The SME that will be analyzed in this paper is "Good Impressions Ltd" (GIL). GIL is a Marketing Agency that currently employs 80 staff members with expansion on the horizon. Established in 2007, GIL is a business based in Buxton (Derbyshire) that has experienced expediential growth over its 10 years of business. This rapid growth has resulted in much of the business's equipment not being updated and only being scaled for demand. The legacy systems currently in operation at GIL are all owned and managed in house. Though GIL's IT department would like to continue to manage their datacenter locally there is little opposition within the board of directors in moving their datacenter offsite as running costs are becoming too high.

Presently, an investment of $£ 25,000$ has been allocated to GIL's IT department for the infrastructure overhaul. James Shaw, the Chief Financial Officer, has advised that the main objective of this investment should be to negate the upsurge in running costs but has also provided no detail on the semantics of achieving this.

Despite the given issues that accompany a siloed infrastructure being IT Sprawl (Defined as a situation in which multiple, under-utilized resources take up more space and consume more resources than can be justified by their workload), high running costs, and problematic scalability other departments have also expressed problems they hope the planned remediation will resolve.

Sales Executives have raised concerns of accessibility when at a Customer Site. GIL's current infrastructure doesn't allow for its employees to access locally stored data from a PC not on the network. The production departments also have problems with the current file servers having insufficient storage (Each requires 2TB). Furthermore, the tower server currently being used for video rendering is expensive to enhance, inconsistently used, and has been sporadically rebooting since July 2016 (6 Months).

\subsection{Stakeholders}

In the section below, there are two tables outlining GIL's Organizational structure and the stakeholder's key comments.

Table 1 - GIL Organization Structure

\begin{tabular}{|c|l|l|}
\hline Department & Title & \multicolumn{1}{c|}{ Name } \\
\hline- & CEO & Frank Smith \\
\hline Finance & CFO & James Shaw \\
\hline Sales & VP & Harry Truman \\
\hline IT & CIO & Jessica Cox \\
\hline Production & DH & Jon Marston \\
\hline & & \multicolumn{2}{l}{}
\end{tabular}

The second table in this section, outlines how the problems discussed in Section 2.1 are aligned to the internal stakeholders at GIL.

Table 2 - Stakeholder's Key Comments

\begin{tabular}{|c|c|}
\hline Name & Comments \\
\hline $\begin{array}{l}\text { Frank } \\
\text { Smith }\end{array}$ & $\begin{array}{l}\text { "Create a greener } \\
\text { infrastructure to enhance the } \\
\text { company's public image" }\end{array}$ \\
\hline $\begin{array}{l}\text { James } \\
\text { Shaw }\end{array}$ & $\begin{array}{c}\text { "A reduction in } \\
\text { datacentre operational costs" }\end{array}$ \\
\hline $\begin{array}{l}\text { Harry } \\
\text { Truman }\end{array}$ & $\begin{array}{l}\text { "More Support for a } \\
\text { mobile workforce and more } \\
\text { storage" }\end{array}$ \\
\hline $\begin{array}{l}\text { Jessica } \\
\text { Cox }\end{array}$ & $\begin{array}{c}\text { "A simplification of } \\
\text { datacentre lifecycle } \\
\text { management and agile } \\
\text { scalability" }\end{array}$ \\
\hline $\begin{array}{c}\text { Jon } \\
\text { Marston }\end{array}$ & $\begin{array}{c}\text { "Document Version } \\
\text { Control and easier file } \\
\text { sharing" }\end{array}$ \\
\hline
\end{tabular}




\subsection{Current Hardware}

The last table below outlines all the hardware (Personal Computers, Telephones etc. excluded) that GIL owns and the problems currently related to them.

Table 3 - Current Hardware \& Utilization

\begin{tabular}{|c|c|c|c|}
\hline Server & Role & Dept. & Problem \\
\hline DNS1 & $\begin{array}{c}\mathrm{AD} \text { and } \mathrm{DNS} \\
\text { Server }\end{array}$ & IT & N/a \\
\hline PRNTSRV & Print Server & IT & Slow \\
\hline DHCP1 & DHCP Server & IT & $\mathrm{N} / \mathrm{a}$ \\
\hline MailSrv & $\begin{array}{r}\text { Exchange } \\
\text { Server }\end{array}$ & IT & $\mathrm{N} / \mathrm{a}$ \\
\hline FS1 & File Server & Finance & $\mathrm{N} / \mathrm{a}$ \\
\hline FS2 & File Server & Sales & $\begin{array}{c}\text { Insufficient } \\
\text { Data } \\
\text { Storage } \\
\text { (Curren } \\
\text { tly } \\
\text { 1TB) }\end{array}$ \\
\hline FS3 & File Server & Prod & $\begin{array}{l}\text { Insufficient } \\
\text { Data } \\
\text { Storage } \\
\text { (Curren } \\
\text { tly } \\
\text { 1TB) } \\
\end{array}$ \\
\hline ProdSrv1 & $\begin{array}{c}\text { Rendering } \\
\text { Tower }\end{array}$ & Prod & $\begin{array}{c}\text { No back-up } \\
\text { / Server } \\
\text { Failure }\end{array}$ \\
\hline
\end{tabular}

\subsection{Summary of Requirements}

After reviewing GIL the following observations were made:

1. The new solution must cost no more than $£ 25,000$ to buy and implement.

2. The new solution must reduce datacenter power consumption.

3. The new solution must resolve the following department issues:

a. The sales and production files servers have insufficient storage and need to be doubled (2TB each) .

b. The Production rendering Server is expensive to maintain and is rebooting sporadically.

c. The Sales Department would like easier Offsite Access to file stored on the network.

d. The Print server requires more compute power.
4. The new solution must simplify IT management and introduce agile scalability.

5. The new solution shall produce a return on investment within 9 years.

6. The Datacenter should remain onsite in Buxton.

Business Objective: "To produce a greener infrastructure that is, easier to manage, consumes less electricity, and costs less to operate.

To measure the fit criteria of the solution proposed in this paper each solution will reference the requirements and business objective listed above.

\section{PUBLIC CLOUD PPROVIDERS}

Cloud Computing is a competitive market with most large enterprises having a stake. Many familiar names in computing such as Adobe, Microsoft, Google and IBM now offer a cloud service. The 3 most successful public cloud providers are Microsoft (Azure / Office 365), Amazon and IBM (Olanubi, 2016) as they currently provide $50 \%$ of the world's cloud computing services (Olanubi, 2016).

Despite all vendors competing in the same field there is little correlation between both the services and and how they charge for them.

In cloud computing the two most popular models are "pay-as-you-go" and "subscription" but each of these models have spawned sub-models for more specific needs. The IaaS or PaaS models implemented by Azure, Amazon AWS and BlueMix tend to be pay-asyou-go but SaaS like Office 365 and Adobe Creative Cloud tend to be Subscription. So with varied choice being a fallacy, there will be five pertinent factors affecting cost with any given solution (Al-Roomi et al., 2013):

1. Initial Costs - The amount of money that a service provider spends to buy the resources*.

2. Lease Period - This is the period in which the customer pays to have those resources allocated to them.

3. QoS (Quality of Service) - This is the set of technologies and models offered by the service provider to enhance the user experience i.e data privacy, availability, support, and redundancies; IaaS, PaaS or SaaS service models.

4. Age of resources - Some vendors will offer 
clusters of resources pooled from legacy hardware for a cheaper price. However, as indicated, this also means newer resources can be pooled and leased at a more expensive price.

5. Bandwidth - Whether a resource is turned off or on, in high demand or low different vendors will commonly adjust their costs accordingly.

\section{*Becoming less common. These costs are often liquidated and covered by the cost of the lease}

When selecting a cloud computing vendor three aspects have to be weighed: Pricing, QoS and Utilization. A customers requirements will subjectively be used to decide what aspect yields the most benefits. Figure 1 included below best displays the components of each aspect and gives an idea to how a public or hybrid cloud solution is priced.

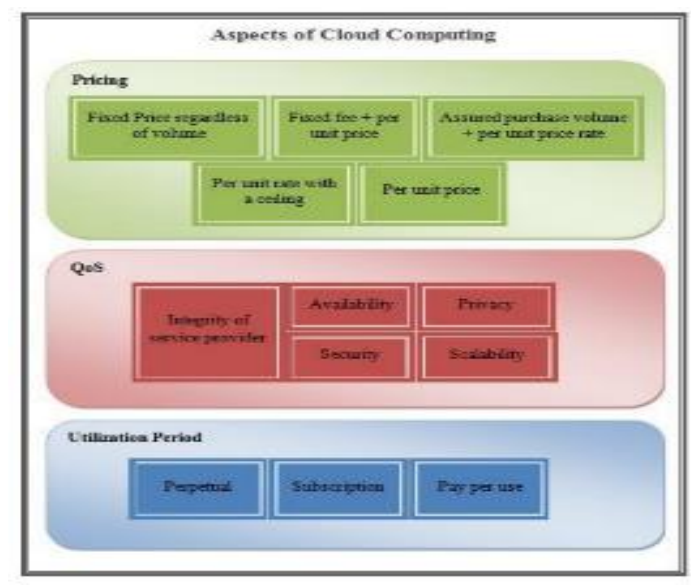

Figure 1 - The Aspects of Pricing Public Cloud

\section{Microsoft (Azure)}

Microsoft Azure has elements of an IaaS and a PaaS (Microsoft, 2017) as it provides Virtual Machines and Windows products such as Windows Server 2012 on demand. Alongside supporting IPv6, Azure also allows a consumer to integrate Office 365, Microsoft's strictly SaaS hosting service for all office suite applications. Both Office 365 and Azure can be adopted separately or as a pair; adopting Office 365 however, is becoming one of the most popular cloud services present in hybrid clouds.

Available in 140 different countries and boosting a Standard Service Level Agreement of $99.95 \%$ (Microsoft, 2017), a standard higher than an independent SME's, Azure is highly practical. However, quantifying a cloud vendor such as Azure is difficult as it includes many features that are subjective thus unquantifiable i.e. license management systems, flexible provisions, layer 7 Load balancing with built in HTTP.

As of 2016 Microsoft has discontinued their subscription based service for Azure. However, the price of the service can be measured by their "pay-asyou-go" model. Using the Azure calculator (Microsoft Pricing calculator, 2017) we know a basic tier server with 1 core, $\sim 2 \mathrm{~GB}$ of RAM and 1TB storage, can be provisioned with a SLA of $99.5 \%$ for $£ 34.12$ a month; $£ 1.14$ a day or $£ 409$ a year. This server would be an alternative to the Sales File server currently in operation at GIL if an extra tb was added and be easily expandable.

\section{Amazon}

"Amazon Web Services" (AWS) is both a SaaS and an IaaS. A reliable cloud service that has been entrusted with hosting Netflix's Media Service. Similar to Azure, AWS offers a pay-as-you-go service that can be paid monthly or be paid upfront for a reduced price. The payment model for AWS is more complex than Azure as acquisition costs, number of total users, and projected number of interactions a second are all factored into pricing. However, using the AWS calculator we know a server on a 3 year lease with 1 core, 2GB of RAM and 1TB storage, can be provisioned for $£ 12.32$ a month; $£ 0.44$ a day or $£ 147.84$ a year. This server would be a cheaper alternative to the Sales File server currently in operation and would be easily expandable.

\section{IBM}

IBM is the third most popular cloud vendor and is the only cloud vendor with a subscription model and the only service to offer all three service models (Olanubi, 2016). Their cloud Service "BlueMix" simplifies Cloud management and makes desirable solutions such as big data analytics easily integratable through pre-built configurations. Much like AWS IBM's payment model is complex as predictable usage can be billed as a subscription or the pay-asyou-go service also factors in usage, bandwidth and more. However, using the IBM calculator we know a server on a 3 year lease with 1 core, $2 \mathrm{~GB}$ of RAM and 1TB storage, can be provisioned for $\$ 98.45$ (£78.60 with an exchange rate of 0.80 ) a month; $\$ 3.28$ a day (£2.63) or $£ 943$ a year. This server would be an alternative to the Sales File server currently in operation and be easily expandable but be much more expensive, even without the extra storage. 


\section{Office 365}

Office 365 is a SaaS, subscription based Microsoft cloud venture. It encompasses all Microsoft office applications plus other productivity services such as Skype for Business, Exchange Online and OneDrive. For $£ 9.40$ a single employee can have access to the aforementioned office applications and services. Office 365 would make an exchange server redundant in an SME as $50 \mathrm{~GB}$ is allocated to each user. With $1 \mathrm{~TB}$ of personal storage allocated to each user and a 1TB Team site (incremented by 50GB per account) file servers could also be retired. However, 80 office 365 subscriptions at $£ 9.40$ is $£ 9,024$ annually. A figure too high for consideration.

\section{Adobe Creative Cloud}

Like Office 365, the Adobe Creative Cloud (ACC) is strictly a SaaS. The purpose of this service is to supply the entire collection of Adobe products from photoshop to Adobe XD. Joining the ACC prompts such benefits as efficient content creation, version consistency, and cloud storage. For an Enterprise, the ACC offers license subscriptions for as little at $£ 11.99$ per person, per month, per application or $£ 38.99$ per person, per month

The business case could greatly benefit from a subscription to this service as it would eliminate onsite storage problems and improve collaboration efforts.

Table 4 - Pros and Cons of Cloud Vendors

\begin{tabular}{|c|c|c|c|}
\hline Company & Approach & Pros & Cons \\
\hline Amazon & $\begin{array}{l}\text { Pay-as-you- } \\
\text { go }\end{array}$ & $\begin{array}{l}\text { Cheapest } \\
\text { IaaS, } \\
\text { reliable }\end{array}$ & $\begin{array}{l}\text { Small } \\
\text { Catalogue } \\
\text { of } \\
\text { services }\end{array}$ \\
\hline Microsoft & $\begin{array}{l}\text { Pay-as-you- } \\
\text { go }\end{array}$ & $\begin{array}{l}\text { Large } \\
\text { Catalogue of } \\
\text { service and } \\
\text { integrates } \\
\text { with Office } \\
365 \\
\text { seamlessly }\end{array}$ & $\begin{array}{l}\text { Unfinishe } \\
\text { d }\end{array}$ \\
\hline IBM & $\begin{array}{l}\text { Subscription } \\
\text { or Pay-as- } \\
\text { you-go }\end{array}$ & $\begin{array}{l}\text { Subscription } \\
\text { Model, } \\
\text { offers all } 3 \\
\text { service } \\
\text { models, } \\
\text { easy to } \\
\text { deploy } \\
\text { solutions } \\
\end{array}$ & Expensive \\
\hline Office 365 & Subscription & $\begin{array}{l}\text { Constantly } \\
\text { updated, }\end{array}$ & $\begin{array}{l}\text { Requires } \\
\text { internet, }\end{array}$ \\
\hline
\end{tabular}

\begin{tabular}{|l|l|l|}
\hline \multirow{2}{*}{\begin{tabular}{l|l} 
Collaborate \\
easily, \\
reduces \\
strain on IT \\
departments, \\
work \\
anywhere
\end{tabular}} & $\begin{array}{l}\text { feature set } \\
\text { changes } \\
\text { forced, } \\
\text { underutili } \\
\text { zation of } \\
\text { functional } \\
\text { ity, } \\
\text { expensive } \\
\text { in bulk }\end{array}$ \\
\cline { 3 - 4 } \\
Creative \\
Cloud
\end{tabular}

All of the public cloud vendors mentioned above are currently available to the general public and common in SMEs. There are many advantages to this cloud solution including:

1. Data availability and Resiliency

2. Technical Expertise and Support

3. Flexibility

4. Inexpensive Initial Costs

5. Resource Optimisation

The three most prominent drawbacks to a private cloud are Data security, constant costs and the fact they never offer a return on investment, only a reduction in spending in some circumstances.

\section{Recommendations}

After analyzing the potential public cloud vendors, it would appear, that for GIL, moving to a public cloud or hybrid cloud isn't cost efficient.

With 80 office subscription being close to $£ 10,000$ and a like for like infrastructure with AWS that doesn't meet the requirements being over $£ 1,500$ there is little attraction to public cloud. Besides there being no upfront costs or the need to remediate servers every 5-9 years, which are a big expense not accounted for in this paper. If the company was smaller a SaaS based public cloud infrastructure could have been a potential solution but not for a SME of GIL's size.

\section{CALCULATING EXISTING POWER CONSUMPTION}

\subsection{Mathematical Optimisation}

To propose the best cloud solution, we must first 
establish the current infrastructure's annual cost projections. This is done by factoring in 2 reoccurring costs. Though lighting, property (if not bought outright), labour, and networking all effect pricing the largest tangible factors of running a datacenter are:

1. Running Costs

2. Cooling Costs

The price of energy will vary by location but in the interest of the business case and this paper, power will hold the constant value of $£ 0.14$ per $\mathrm{kWh}$ (Average cost per kWh of electricity in the UK according to the Energy Saving Trust, March 2016).

As GIL is one of the many partners of Hewlett Packard Enterprise all their servers have been bought from HPE and can thusly have their power consumption estimated through the "HPE Power Assist Tool". To apply the business case, we must calculate the total power usage of the 7 rack servers and 1 tower server. The rack servers currently in production are all "Proliant DL380 G6s" and the tower server currently in operation is a "ProLiant ML370 G6". The Proliant DL380 G6's max Watt Usage per hour, is $131.11 \mathrm{~W}$ and the Proliant ML370 G6's max is 425.32 .

Table 5 - GIL's Total Wattage

\begin{tabular}{|c|c|c|c|}
\hline Model & Watt & Amount & Total Watt \\
\hline $\begin{array}{c}\text { Proliant } \\
\text { DL380 G6 }\end{array}$ & $\mathbf{1 3 1} \mathbf{~ W}$ & $\mathbf{7}$ & $\mathbf{9 1 7 . 7 7}$ \\
\hline $\begin{array}{c}\text { ProLiant } \\
\text { ML370 G6 }\end{array}$ & $\mathbf{4 2 5 ~ W}$ & $\mathbf{1}$ & $\mathbf{4 2 5 . 3 2}$ \\
\hline \multicolumn{4}{|c|}{ Total } \\
\hline
\end{tabular}

\section{Running Costs}

After receiving the datacenter's Watt usage per hour, it is possible to calculate the annual costs using the formula below to convert power consumption figures into, kilwatts and then running costs:

$\left(\frac{\text { Uperating Hours * Watt Usage Fer Hour }}{1 \text { nnn }}\right)=k W W^{*}$ Electricity CostperkWh (1)

Using this formula, we can calculate the annual running cost of the datacenter to be $£ 1647.17$.

\section{Cooling Costs}

Cooling costs are the second quantifiable factor that can be measured to analyse a company's operational costs. To do this we must know how many British Thermal Units the datacenter produces. A British Thermal Unit
(BTU) is defined as the amount of energy needed to raise the temperature of 1 pound of water by 1 degree Fahrenheit. The following formula can be used to calculate a datacenters BTU:

$B T U=$ Watts $* 3.14(2)$

Since we have already establishing that GIL uses 11,757 Kilo Watts per hour we can use the cooling cost formula to calculate the Datacenter's BTU; 4217.30026 BTU.

After establishing both a datacenters Watt usage and BTU the following widely used formula can be used to calculate, kwh then cooling costs:

$\left(\frac{(O \text { perating Hours } * \text { BTU per hour }) * 0.293}{1000}\right)=k W h$ *
Electricity Costs per $k W h$

Using this formula, we can estimate that a minimum of $£ 1515.43$ a year is being spent on cooling.

Adding this figure to the running costs we can establish that the annual cost of running and cooling GIL's datacenter is $£ 3,162.59$.

\subsection{Creating and Costing a Private Cloud}

To create a private cloud one must attain the components that make a private cloud possible. GIL is a partner of HP so for this paper we will be converging their infrastructure using HP software and hardware when appropriate.

\section{Converged Infrastructure Cost}

To attain a private cloud GIL could virtualize and consolidate their current infrastructure, add storage, install relevant software and have a private cloud. However, this project's objective involves considering the longevity of the datacenter and missing an opportunity to reduce cabling, reduce consumption and easy future scalability would be counterproductive.

For this reason, attaining the following hardware and software displayed in table 6 has been proposed to optimize efficiency, reduce operational costs and enhance flexibility. 
Table 6 - Cost of Converged Infrastructure Cloud

\begin{tabular}{|c|c|}
\hline Software & Cost \\
\hline Windows Server 2008 R 2 x 2 & $\mathrm{~N} / \mathrm{a}$ \\
\hline Convergence Tool (OneView) & Free \\
\hline Cloud Platform (OpenStack) & Free \\
\hline $\begin{array}{l}\text { VSphere Essential Kit (No } \\
\text { Vcentre, } 3 \text { servers with } 2 \text { cores } \\
\text { each license) }\end{array}$ & $£ 430.50[30]$ \\
\hline $\begin{array}{l}\text { HPE BLc3000 Enclosure (2 } \\
\text { Pwr, } 6 \text { fans) }\end{array}$ & $£ 5,443[26]$ \\
\hline $\begin{array}{l}\text { HPE ProLiant BL660c Gen9 } \\
(20 \text { Cores, 64GB Ram, 1TB) }\end{array}$ & $£ 10,290[27]$ \\
\hline HPE Storageworks D2200sb & $£ 1,368.42[28]$ \\
\hline $9 \times 1$ 1TB 6G SATA & $£ 1,251.72[29]$ \\
\hline Networking and Cabling & $\mathrm{N} / \mathrm{a}$ \\
\hline
\end{tabular}

GIL's current infrastructure has 18 Cores, 18GB of RAM, 8TB of storage and no redundancies. By having no power or cooling redundancies GIL datacenter would be considered a Tier I datacenter.

If GIL were to purchase the proposed technology in table 6 their datacenter would have a resource pool of 20 Cores, 64GB of RAM and 11TB of storage, with power and cooling redundancy. Thus, classifying the new infrastructure as a tier II datacenter. Additional memory has been added to host new software and give Production and Sale an extra TB of storage. One core has also been allocated to the print server to enhance processing power.

Using HPE's "Power Advisor" and the formulas mentioned in earlier section we can calculate the private cloud's operational costs to be $£ 1,843$ a year $(13,169$ Kw), $£ 1,318.87$ less $(9,420 \mathrm{kw}$ less $)$.

\section{SOLAR TECHNOLOGY}

As public image makes or breaks a company and the future price of electricity becomes unpredictable exploiting solar energy to produce electricity is becoming a widely-adopted greener alternative to the grid.

Breeze claims that, despite incurring few early adopters due to high initial costs, skepticism and fears of inefficiency, solar power has really grown in the last three decades. However, it's important to note that solar power still isn't an all-encompassing solution to the grid. There are four key factors that one needs to consider outside of cost when analyzing a solar powered infrastructure.

The first factor is, the direction/ angle of the roof, second, any shading that could impede on production, third, the space allocated to the solar panel installation and finally, the time of year. In some hotter countries temperature will also have to be considered as a fifth factor to insure panels don't over heat, fortunately for the UK however, this isn't a worry.

In this paper, the business case experiences no space limitation and no hard shading. For this reason, an accurate cost benefit analysis can be made from the following main considerations: Solar panels cost \& efficiency, hours of sunlight, and the angle of the panels.

\subsection{Solar Panels Cost \& Efficiency}

Akin to all other fields of technology there is a plethora of hardware that all try to achieve a common goal. In Solar Technology, there are many types of solar panels currently in production. The three most popular panels according to the Eco Experts are: Monocrystalline, Polycrystalline and amorphous ("Thin Film").

Each manufacturer should provide an in-situ efficiency rating for what's possible on a typical installation, called the PTC (Performance Test Conditions) rating. Efficiency ratings are established in a lab by projecting 100 Watts of sun light on to a solar panel and measuring the output; normally between $10-20 \%$. According to the eco expert, PTC rating have an accuracy rating of 85$95 \%$. For this reason, all efficiency rating in this paper will be deducted the average; $10 \%$.

\section{Monocrystalline}

The Eco Experts defines Monocrystalline solar panels as using wafer thin cuts of silicon crystals. Since monocrystalline panels are made out of the highest-grade silicon and cut under strict guidelines they're known to produce the highest levels of efficiency. SunPower, a prolific manufacturer of Monocrystalline Panels, has achieved record breaking efficiency ratings of $21.5 \%$ PTC on their latest X21-345 model.

Described as the "cleanest panels" on the market Monocrystalline solar panels also have the longest warranties and take up the least space due to their high efficiency. There would be little competition to be had in this section of the paper if they also weren't the most expensive panels to manufacturer and purchase. 
SunPower do not publicly publish the cost of their solar panels so this panel will not be used in the comparison, as a substitute the Perlight PLM-300M-60 MONO will be used instead.

\section{Table 7 - Information Taken from the Product Information page on BuyPVDirect.}

\begin{tabular}{|l|l|}
\hline Model & $\begin{array}{l}\text { PerLight PLM-300M-60 } \\
\text { MONO }\end{array}$ \\
Max. Output & $300 \mathrm{w}$ \\
Max. Efficiency & $18.9 \%$ \\
Cell Count & $60(6 \times 10)$ \\
Warranty & 25 year Guarantee \\
Other & $\begin{array}{l}\text { The most efficient panels } \\
\text { in this paper. }\end{array}$ \\
\hline Price & $£ 165(£ 198$ with VAT) \\
\hline
\end{tabular}

\section{Polycrystalline}

The process of producing polycrystalline panels is not as sophisticated as producing Monocrystalline panels. Polycrystalline Panels are made using the off cuts of different silicon melted down into a mould to form their semiconductor. They're less efficient than their monocrystalline competitor but this efficiency gap has become less noticeable in recent years.

According to the Eco Expert, the most efficient polycrystalline panels are produced by SunTech. In 2016 SunTech released the STP265/WEM, a polycrystalline solar panel with $16.3 \%$ efficiency. Sadly, these panels aren't currently avaliable to purchase so the following SunTech panels have been selected as a close substitute:

\section{Table 8 - Information Taken from the Product information page on BuyPVDirect.}

\begin{tabular}{l|l|}
$\begin{array}{l}\text { Model } \\
\text { Max. Output } \\
\text { Max. Efficiency }\end{array}$ & SunTech STP280-24 \\
Cell Count & $150 \mathrm{w}$ \\
Warranty & $72(6 \mathrm{x} 12)$ \\
Other & ---- \\
\hline Price & $\begin{array}{l}\text { The most cost efficient } \\
\text { panel on BuyPVDirect }\end{array}$ \\
\hline & $£ 105(£ 126$ with VAT) \\
\hline
\end{tabular}

\section{Amorphous}

Amorphous or "thin film" solar panels are a newer technology than crystalline and polycrystalline panels. They are made by placing several thin layers of photovoltaic material onto a substrate. They are the cheapest panels in this paper and the least efficient. They're flexible and are rarely implemented for longevity. Depending on the technology, thin-film module prototypes have reached efficiencies between 7 $13 \%$ and production modules operate at about $9 \%$. Thus proving the claim that monocrystalline panels can be four times more efficient than Amorphous (thin-film) based solar panels. With efficiency levels this low, amorphous panels will not be included in price comparisons.

\subsection{Hours of Sunlight (Buxton, Derbyshire)}

The United Kingdom and Sunshine are often treated as two mutually exclusive terms. However, though solar panels produce more power in countries such as Spain or South Africa, solar panels still function in the UK. Their output is hindered by rain, overcast and shorter days but most solar panels still provide a return on investment within seven years.

To engineer a solar powered solution to cover GIL's operational costs it is important to know the amount of sunlight that is bestowed on their offices. Suitably, The Met office has been monitoring the average amount of sunlight in Buxton Derbyshire since 1981 to 2010; using this data the following table has been produced.

Table 9-A table to show the Annual Sunshine in Buxton, Derbyshire.

\begin{tabular}{|l|l|}
\hline Month & Sunshine (hours) \\
\hline Jan & 41.2 \\
\hline Feb & 63.1 \\
\hline Mar & 93.8 \\
\hline Apr & 140.2 \\
\hline May & 180.2 \\
\hline Jun & 166.4 \\
\hline Jul & 178.5 \\
\hline Aug & 167.6 \\
\hline Sep & 123.8 \\
\hline Oct & 91.4 \\
\hline Nov & 51 \\
\hline Dec & 37.7 \\
\hline Annual & $1334.8(1335 r)$ \\
\hline
\end{tabular}

Table 9 shows us that annually we can expect 1335 hours of sunlight to be shed on GIL's offices. This equates to a mean of 3.71 hours of sunlight per day. This is essential knowledge as with most solar panels producing a test 
conditions efficiency rating of 10-20\%, every hour needs to be considered and consumed.

\subsection{Panel Elevation}

Leading us to the next section, to get the most from solar energy, it is essential to point the panels in the direction that captures the most sun. Though tracking panels that follow the sun are a possible solution as they have been proven to increase solar production by $10 \%$ in the winter and $40 \%$ in the summer when compared to stationary panels. They're often expensive, unreliable, and implemented on the ground for space efficiency. As GIL is installing their panels on the roof of their office, require a quick return on investment and claim space "shouldn't be an issue", the best case solution in this instance are manual tilt panels.

By analyzing the data presented to us in figure 2 we can start to understand the amount of potential solar energy lost to inefficiencies and see the potential benefit of adjusting panels.

In Figure 2 the $\mathrm{Y}$ axis is the suns elevation in the sky and the $\mathrm{X}$ axis is the location of the sun in the sky. Through knowing this we can clearly see there is more sunlight in the Summer (Jun) than there is in the Winter (Dec). Figure 2 also visualizes what may seem obvious: the angle of the panels in relation to the angle of the sun and time spent in its direct raise effects power out. For an efficient implementation of solar panels we need to establish both what angle to install the panels and what direction. Though establishing the direction to install panels is common knowledge in the solar community the angle isn't.

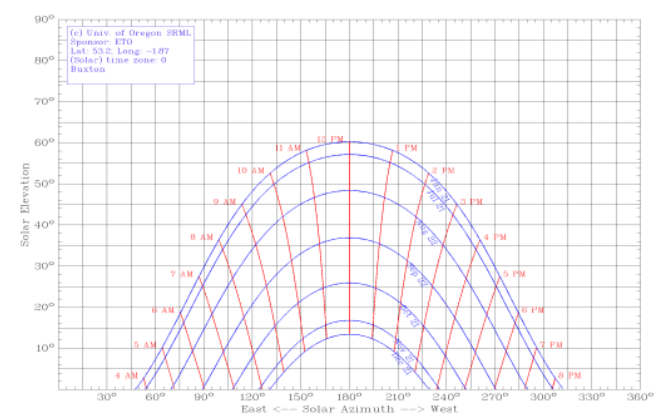

Figure 2 - A graph of the sun path in Buxton, Derbyshire. Generated using a tool from the University of Oregon
Like how moss grows on trees, solar panels in the northern hemisphere will be facing true south and in the southern hemisphere solar panels will be facing true north. If GIL were to implement south facing solar panels on fixed brackets their optimum efficiency would be $71.1 \%$. If they implemented adjustable brackets and adjusted them once in the summer and once in the winter, they would see a $4 \%$ increase in their solar harvest. Adjusting the bracket any more than twice, let's say four times, would increase efficiency by $0.4 \%$ but the amount of effort required for such a diminished return means it's rarely implemented and won't be implemented in this paper. Therefore GIL's solar panels will be adjusted twice: once on the $30^{\text {th }}$ of March and again on the $12^{\text {th }}$ of September.

The perfect angulation of the panels according to the data presented in Figure 2 and the information provided from Landua's research is 28.3 in summer and 65.6 in winter.

\section{Recommendation}

Examining the two panels proposed in this section one would assume that at a glance the Perlight is the supreme panel. Though the Perlight PLM-300M-60 MONO is more efficient, has a higher max output and takes up less space, the cost being true to monocrystalline panels is much more expensive.

Applying simple math we can deduce that the Perlight panels on implementation delivering a 300 watt max output for $£ 126$ a panel produce 1.51 Watts per $£ 1$ spent. SunTech's STP280-24 on the other hand produce 2.2 watts per $£ 1$ spent.

After selecting the SunTech's STP280-24 solar panels as the preferred panel we now need to calculate how many panels will be required to produce enough energy for the private cloud aforementioned in section 4.2. The private cloud infrastructure designed in 4.2 requires $13169.4 \mathrm{Kw}$ a year. To produce this much energy from 1335 hour of sunlight, 33 Suntech panels costing $£ 4,143.18$ will be required. At this point however, It's important to mention that none of the calculations in this paper have considered labour costs. 


\section{PROPOSED SOLUTION}

\subsection{A Cloud Ready Infrastructure Powered Via Solar Panels}

As the IT department wishes to host their datacenter locally and public cloud have proven unaffordable the following solution has been produced. The final solution designed in section 4.2 will be implemented in line with the solar solution devised in section 5 . The annual energy requirements for the new datacenter are estimated to be $13,169 \mathrm{~kW}$ a year. To satisfy this requirement and attain a private cloud the following components need to be purchased 33 SunTech STP280-24 (£4,143.18).

- $\quad$ Adjustable mount brackets (N/a)

- Installation Labour (N/a)

- Maintenance (N/a)

- OneView (N/a)

- OpenStack (N/a)

- VSphere Essential Kit(£430.50)

- HPE BLc3000 Enclosure $(£ 5,443)$

- HPE ProLiant BL660c Gen9 (£10,290)

- $\quad$ HPE Storageworks D2200sb $(£ 1,368.42)$

- 9 x 1TB 6G SATA (£1,251.72)

- $\quad$ Networking and Cabling (N/a)

- Labour (N/a)

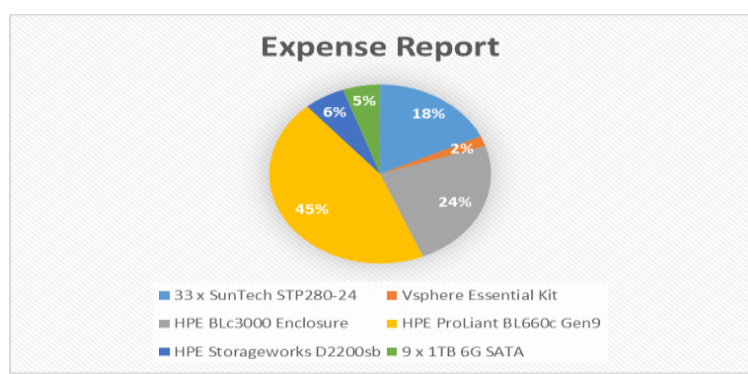

Figure 3 - A graph showing the cost of each component required to provide the solution

With the HPE partner's discount the total cost of the private cloud infrastructure is $£ 17,030.80$. The total cost of the Suntech solar panels is $£ 4,143.18$. A total of $£ 25,000$ pounds was allocated to reducing operational costs and achieving the requirements mentioned in earlier section and a total of $£ 21,173.98$ is required for this solution. Despite the private cloud infrastructure reducing power consumption by over $50 \%$ introducing it without solar power wouldn't be cost efficient. The following graph (Figure 4) displays the payback period and return over the proposed 9 year limit. It is important to note that unlike many

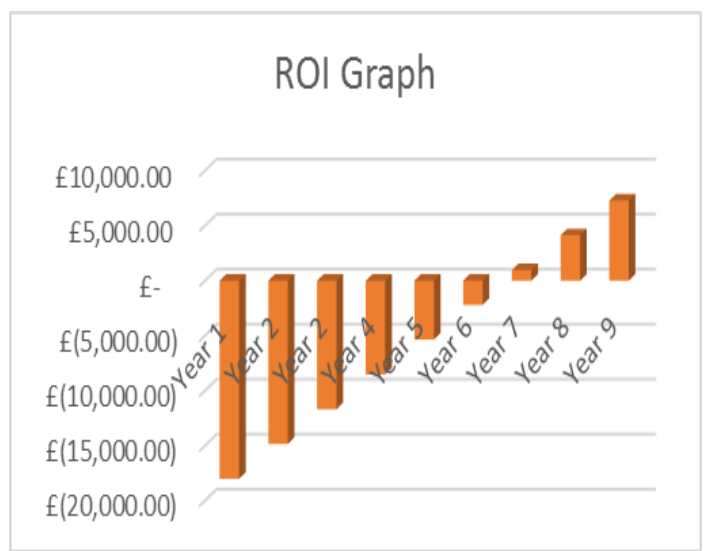

Figure 4-A bar chart displaying the retrun on Investment for Solution 1

other investments an investment in solar has immediate return from the day it's installed.

Figure 5 was produced assuming the solar panels are installed on the $1^{\text {st }}$ of January 2017. At a glance an observer would assume the solution offers a return on invest in the last quarter of 2024, however figure 3 does not account for Net Present Value (NPV). NPV is the difference between the present value of cash inflows and the present value of cash outflows. To put it simply, the cash invested in 2017 will not be equal to same amount in 2024. To calculate the NPV the following formula has been implemented:

$$
N P V=\sum_{t=1}^{T} \frac{C_{t}}{(1+r)^{t}}-C_{0}
$$

$\mathrm{C}_{\mathrm{t}}=$ net cash inflow during the period $\mathrm{t}$

$\mathrm{C}_{\mathrm{o}}=$ total initial investment costs

$\mathrm{r}=$ discount rate

$\mathrm{t}=$ number of time periods

Using this formula we can establish that though the project's return on investment is $£ 7,289.33$ at the end of the $9^{\text {th }}$ year, the actual return on investment after account for the NPV with a discount rate of 3.5 is $£ 2,886.01$.

It is critical to this solution that the infrastructure is reformed and the solar panels are installed in order to achieve the business requirements and a return on investment. Figure 4 shows how the savings are divided. Showing that if either were implemented separately there wouldn't be a return on invest within 7 years. 


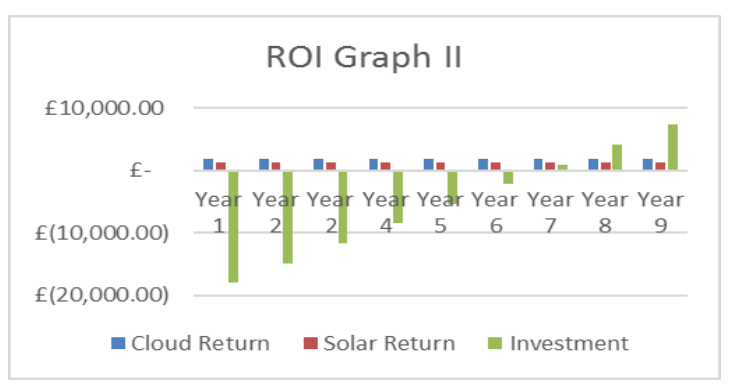

Figure 5 - A graph showing the cost of investment and savings from both the cloud infrastructure and solar panels associated with solution one

When compared to the six requirements listed in section 2.4 we can be assured that the following requirements have been met:

- R1: The Solution costs less than $£ 25,000$ (£21,173.98)

- R2: The Solution reduces power consumption by $58 \%$

- R3: The Solution provides the required memory, a reliable virtual rendering server, the new file servers will be running Microsoft's Onedrive allowing office access and file consistency. One of the two redundant cores could also be assigned to the print server to resolve print issues.

- R4: The solution simplifies IT management lifecycles through consolidating resources and allowing for the introducing of automation.

- R5: The solution provides an undeniable return on invest within 9 years (NPV - $£ 2,886.01$ )

- R6: The solution is installed in their Buxton offices meeting the soft requirement presented by the IT department.

\section{CONCLUSIONS}

To conclude, in this paper, we intended to develop an understanding of cloud, virtualization, solar power and the potential benefits they could bring to an SME keen on reducing their operational costs. The fictitious business featured in this paper had requirements that were common in siloed infrastructures and were also commonly resolved through cloud implementation.

At first, implementing a private cloud for GIL was an unattractive prospect as it was found to have high initial costs and a slow return on invest. However, with the implementation of solar panels this paper found private clouds to offer the largest return on investment over nine years without compromising on scalability, consolidated management or the customer's requirements.

Public clouds, despite seeming like a valid option in the beginning, appeared to be a poor investment for an enterprise of this size. Nonetheless, the consensus gained in this paper is that though they offer poor return for SME they have the potential to provide benefits to small businesses, large business and SME's willing to incur costs for an agile infrastructure scalability and automated management lifecycles.

For enterprises that, wish to retain an on-site datacenter, demand a return on investment, and insist on low power consumption we suggest the solution proposed in this paper.

\section{REFERENCES}

E. Brown and G. Swenson, "Final version of NIST cloud computing definition published," in NIST, NIST, 2016. [Online]. Available: https://www.nist.gov/newsevents/news/2011/10/final-version-nist-cloudcomputing-definition-published. Accessed: Feb. 6, 2017.

O. T. P. Ltd, "Converged infrastructure and cloud @ Oriel," in Oriel, 2016. [Online]. Available: http://www.oriel.com.au/converged_infrastructure_and_c loud. Accessed: Feb. 6, 2017.

"Blade server systems - HPE BladeSystem blade server technology," in HPE, 2017. [Online]. Available: https://www.hpe.com/us/en/integrated-

systems/bladesystem.html. Accessed: Feb. 6, 2017.

HPE Technology, "Your infrastructure automation engine: HPE OneView 3.0," in YouTube, YouTube, 2016. [Online]. Available: https://www.youtube.com/watch?v=Tz1jAAo2H_4.

Accessed: Feb. 6, 2017.

"Become a Cloud Service Broker," Hewlett Packard Enterprise Development LP, Nov. 2015. [Online]. Available:

https://www.hpe.com/h20195/v2/GetPDF.aspx/4AA51140ENN.pdf. Accessed: Feb. 7, 2017.

M. J. Kavis, Architecting the cloud: Design decisions for cloud computing service models (SaaS, PaaS, and IaaS). 
United States: John Wiley \& Sons, 2014.

B. Software, "Cloud Lifecycle Management," in "Cloud Lifecycle management is transforming digital enterprises," BMCSoftware, USA, 2005. [Online]. Available:

https://www.google.co.uk/url?sa=t\&rct=j\&q=\&esrc=s\&s ource $=$ web $\& c d=1 \&$ cad $=$ rja $\&$ uact $=8 \&$ ved $=0$ ahUKEwiE mKeBIIHSAhUI6mMKHRUKCScQFghHMAA\&url=ht tp $\% 3 \mathrm{~A} \% 2 \mathrm{~F} \% 2 \mathrm{Fwww}$. bmcsoftware.uk\%2Fitsolutions $\% 2$ Fcloud-lifecyclemanagement.html\&usg=AFQjCNGKjbDG7HfpTpvi6ga U2RCq-flAPQ. Accessed: Feb. 8, 2017.

M. Al-Roomi, S. Al-Ebrahim, S. Buqrais, and I. Ahmad, "Cloud computing pricing models: A survey," International Journal of Grid and Distributed Computing, vol. 6, no. 5, pp. 93-106, 2013. [Online]. Available:

http://www.sersc.org/journals/IJGDC/vol6_no5/9.pdf. Accessed: Feb. 8, 2017.

S. Olanubi, "Top 5 largest cloud companies in the world - Tharawat magazine," in Facts, Tharawat Magazine, 2016. [Online]. Available: https://www.tharawatmagazine.com/facts/top-5-largest-cloud-companiesworld/\#gs.h6H24PA. Accessed: Feb. 10, 2017.

Microsoft, "Azure purchase FAQ | Microsoft azure," 2017. [Online]. Available: https://azure.microsoft.com/en-us/pricing/faq/. Accessed: Feb. 11, 2017.

[11] Microsoft, "Pricing calculator | Microsoft azure," 2017. [Online]. Available: https://azure.microsoft.com/en- 2017. 